\title{
Super-resolution microscopy in studying neuroendocrine cell function
}

\author{
Anneka Bost ${ }^{1}$, Mathias Pasche $^{2}$, Claudia Schirra ${ }^{1}$ and Ute Becherer ${ }^{1 *}$ \\ Physiologisches Institut, Universität des Saarlandes, Homburg/Saar, Germany \\ ${ }^{2}$ Division of Neurobiology, MRC Laboratory of Molecular Biology, Cambridge, UK
}

Edited by:

Stephane Gasman, CNRS, France

Reviewed by:

Valentin Nägerl, Université Bordeaux

Segalen, France

Corey Smith, Case Western

Reserve University, USA

\section{*Correspondence:}

Ute Becherer, Physiologisches

Institut, Universität des Saarlandes, Kirrberger Strasse, Geb. 59,

D-66421 Homburg/Saar, Germany

e-mail: ute.becherer@uks.eu
The last two decades have seen a tremendous development in high resolution microscopy techniques giving rise to acronyms such as TIRFM, SIM, PALM, STORM, and STED. The goal of all these techniques is to overcome the physical resolution barrier of light microscopy in order to resolve precise protein localization and possibly their interaction in cells. Neuroendocrine cell function is to secrete hormones and peptides on demand. This fine-tuned multi-step process is mediated by a large array of proteins. Here, we review the new microscopy techniques used to obtain high resolution and how they have been applied to increase our knowledge of the molecular mechanisms involved in neuroendocrine cell secretion. Further the limitations of these methods are discussed and insights in possible new applications are provided.

Keywords: chromaffin cell, membrane capacitance, amperometry, TIRFM, SIM, PALM, STORM, STED

\section{INTRODUCTION}

The main function of neuroendocrine cells, e.g., chromaffin cells, is the regulated release of hormones or peptides into the blood stream. This function is well documented in several reviews (Becherer and Rettig, 2006; Stevens et al., 2011; Jahn and Fasshauer, 2012; Kasai et al., 2012). Briefly, regulated exocytosis is a multi-step process controlled by calcium (Figure 1A). In order to fuse, large dense core vesicles (LDCVs) containing catecholamines approach the plasma membrane (PM) along actin filaments (Villanueva et al., 2012). They dock to the PM to the target-SNARE (t-SNARE) acceptor complex composed of syntaxin1 and SNAP-25, via synaptotagmin (de Wit, 2010). This process is controlled by Munc18 which acts at several steps during exocytosis (Rizo and Sudhof, 2012). After docking LDCVs undergo maturation reactions in which the vesicular SNAREs, vesicle associated membrane protein 2 and 3, also called synaptobrevin and cellubrevin, associate with the t-SNAREs to form the SNARE core complex. This reaction, that stably binds LDCVs to the PM, is regulated by a variety of proteins such as $\mathrm{Ca}^{2+}$. dependent activator protein for secretion (CAPS), complexin, snapin or tomosyn (Becherer and Rettig, 2006). Upon increase of $\mathrm{Ca}^{2+}$ above a concentration of $0.5-0.9 \mu \mathrm{M}$, fusion is initiated by the interaction of synaptotagmin with the SNARE complex and the PM (Sudhof, 2012). Proteins such as complexin control this reaction. After exocytosis, the LDCV membrane and protein components are taken up via clathrin dependent endocytosis and processed through poorly understood recycling (Becherer et al., 2012). The development of this rather complex model of the exocytosic pathway was enabled by an array of innovative measurement methods that were applied to neuroendocrine cells.

\section{METHODS TO STUDY CHROMAFFIN CELL FUNCTION}

In neuroendocrine cells, regulated exocytosis has been studied since the late 1960s using biochemical methods (Schneider et al.,
1967). Among other important findings, researchers were able to describe the $\mathrm{Ca}^{2+}$-dependency of exocytosis (Pollard et al., 1982). The pace of research in this field greatly picked up with the launch of high time resolution measurement methods. In 1982 using patch-clamp electrophysiology, Neher and Marty (1982) were able to measure changes in the membrane capacitance of chromaffin cells that corresponded to either the addition (exocytosis) or subtraction (endocytosis) of vesicular membrane to the PM. Using complex depolarization protocols (Gillis et al., 1996; Voets et al., 1999) or flash photolysis of caged $\mathrm{Ca}^{2+}$ (Kaplan and Ellis-Davies, 1988; Neher and Zucker, 1993) it was possible to dissect four main functional pools of LDCVs termed reserve pool, unprimed pool (UPP), slowly releasable pool (SRP) and readily releasable pool (RRP) (Figure 1B1). It was hypothesized that LDCVs dock to join the UPP and that while priming occurs, LDCVs proceed in a sequential manner through SRP and RRP (Sorensen, 2004). The molecular machinery mediating these reactions was dissected using gain or loss of function assays (Becherer and Rettig, 2006). Ten years after establishing membrane capacitance recording, carbon fiber amperometry was developed (Wightman et al., 1991). With this technique the release of oxidizable neurotransmitters or hormones such as catecholamines from individual LDCVs can be measured with very high temporal resolution (Bruns and Jahn, 2002). The derived kinetics of release were used to identify proteins such as synaptobrevin, that play a role in fusion pore opening during exocytosis (Borisovska et al., 2005) (Figure 1B2). By combining carbon fiber amperometry with membrane capacitance recording, it was then possible to discriminate between exo- and endocytosis when they occur simultaneously (Borges et al., 2008). Furthermore, this combination was instrumental in uncovering the role of for example CAPS in loading LDCVs with catecholamines (Speidel et al., 2005).

The main limitation of both methods is that they measure directly the very last step of exocytosis and they provide only little 


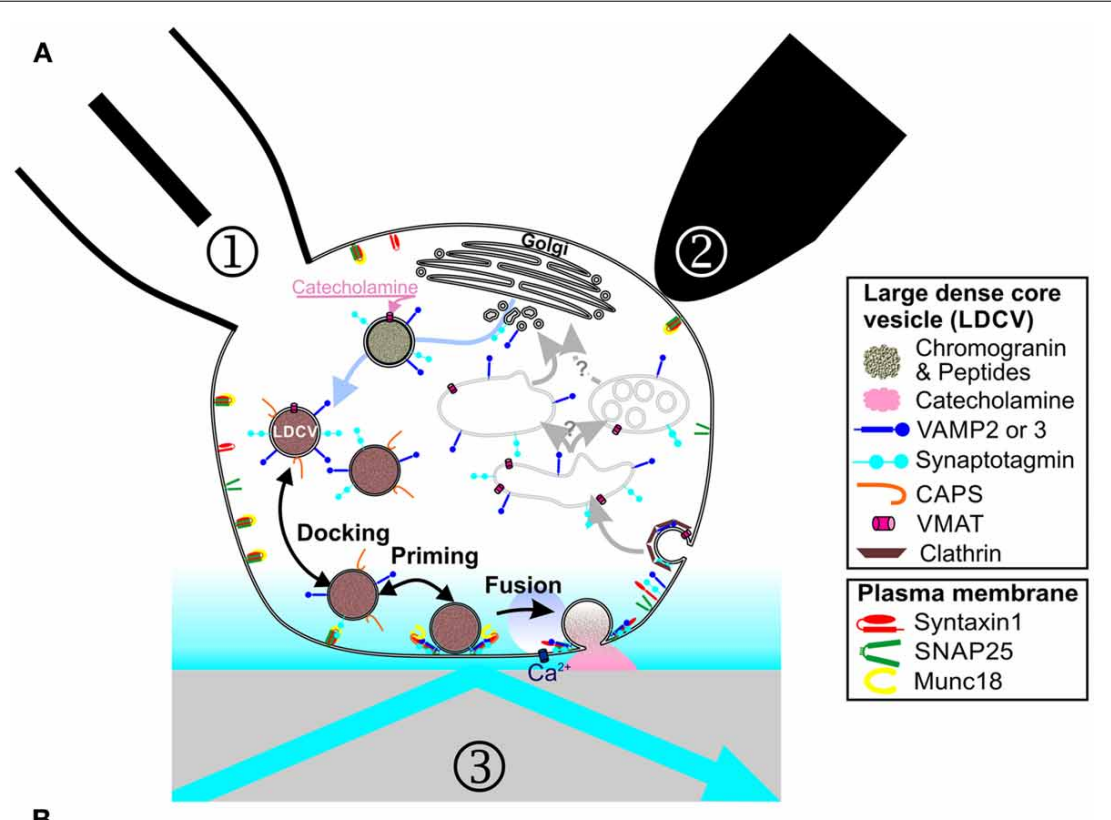

B

1. Membrane capacitance recording

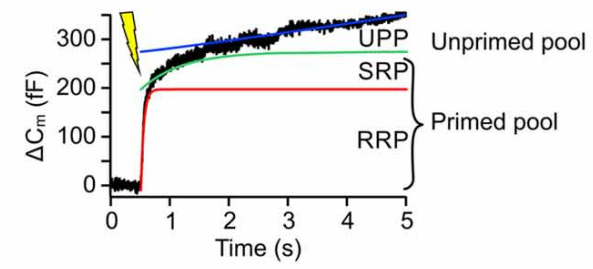

3. TIRFM

2. Carbon fiber amperometry

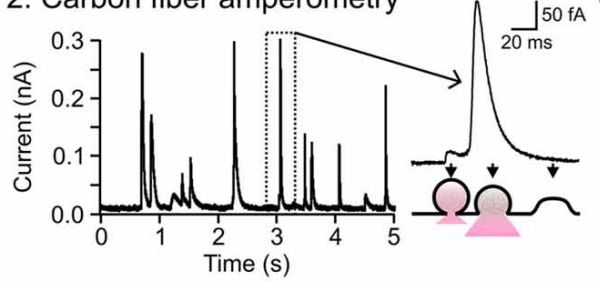

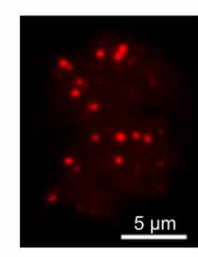

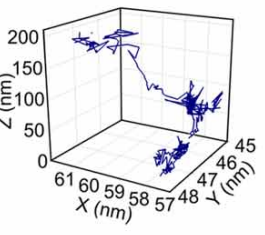

4. Electron microscopy

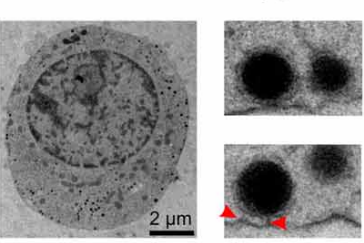

FIGURE 1 | Current methods to study regulated exocytosis in chromaffin cells. (A) Model of regulated exocytosis in chromaffin cells depicting a number of proteins involved in the process. Exocytosis of LDCVs can be monitored by (1) membrane capacitance through patch clamp electrophysiology, (2) carbon fiber amperometry and (3) TIRFM. (B) Example of exocytosis measurement in chromaffin cells. (B1) Representative trace of a membrane capacitance recording in which exocytosis was induced by flash photolysis of caged $\mathrm{Ca}^{2+}$. Three functional pools can be determined by fitting the data with 3 components: a fast exponential (RRP, red line), a slow exponential (SRP, green line) and a linear regression (UPP, blue line).
(B2) Release of catecholamines from single LDCVs can be observed as individual spikes by carbon fiber amperometry (left). The spike shape provides information about the fusion pore opening (right). (B3) TIRFM picture of a bovine chromaffin cell expressing NPY-mCherry (left). Due to the high signal to noise ratio, the LDCVs can easily be seen as individual spots. They can be tracked over time thus revealing a complex behavior (right). (B4) Electron micrograph of an embryonic mouse chromaffin cell, fixed using high-pressure freezing method (left). The close up of some LDCVs shows astounding morphological details (right). Red arrows indicate fine tethers that appear to bridge the LDCV and the plasma membrane. information about docking. Electron microscopy (EM) is therefore often used to complement this information (Ashery et al., 2000; Yizhar et al., 2004; de Wit et al., 2009). Vesicles are considered morphologically docked if they are touching the PM or located within $30 \mathrm{~nm}$ distance to the PM (Verhage and Sorensen, 2008; de Wit, 2010). These vesicles can belong to all three functional pools UPP, SRP or RRP. The development of a fixation method involving high-pressure freezing produced nearly artifact free, highly preserved cell morphology (Studer et al., 2001;
Vanhecke et al., 2008). Electron micrographs of chromaffin cells fixed with this method, revealed fine structures at the contact regions between LDCVs and the PM, which might correspond to assembled SNARE proteins (Figure 1B4). Due to this increased resolution a new morphological classification was introduced of docked and tethered vesicles (Verhage and Sorensen, 2008). Until now it was not possible to clearly associate a functional pool to those two morphologically different pools of LDCVs, thereby generating quite some confusion in the field. 
In the 1990s total internal reflection fluorescence microscopy (TIRFM) was first introduced in the field of exocytosis (Axelrod, 1981; Steyer et al., 1997; Oheim et al., 1998; Oheim and Stuhmer, 2000). It is used to visualize individual LDCVs approaching the PM and their fusion. The principal feature of TIRFM is that a thin evanescent field of light with decaying exponential excitation energy is generated at the interface of the glass coverslip and the cell. Thus, excitation of fluorophores is restricted to a shallow layer close to the PM (Figure 1B3). This technique provides an axial (z) resolution well below $100 \mathrm{~nm}$, while the lateral (x, y) resolution is about $250 \mathrm{~nm}$. The highly contrasted pictures of individual fluorescently labeled LDCVs and the possibility to follow them over time raised very high expectations that TIRFM would provide profound insights in the molecular machinery of docking and priming (Steyer et al., 1997; Oheim and Stuhmer, 2000; Johns et al., 2001). This turned out to be much more complex than originally anticipated (Oheim and Stuhmer, 2000; Nofal et al., 2007). TIRFM helped to understand the role of Munc18-1 (Toonen et al., 2006) and $\mathrm{Ca}^{2+}$ (Pasche et al., 2012) during docking, and the function of tomosyn in priming (Yizhar and Ashery, 2008).

Taken together, using a combination of membrane capacitance recording, carbon fiber amperometry and EM very effectively uncovered the function of several proteins, such as the SNARE proteins or Munc13, which play a role at only one step of exocytosis in chromaffin cells. TIRFM helped to examine the function of certain proteins or substances, such as Munc18 or $\mathrm{Ca}^{2+}$, that mediate several steps of exocytosis. However, the results of these studies become more and more complex to interpret as we investigate the role of proteins that appear to be involved throughout exocytosis, e.g., Synaptotagmin. The question is whether superresolution microscopy can help in this quest by providing a link between morphological (EM) and functional data (membrane capacitance recording, carbon fiber amperometry or TIRFM).

\section{SUPER-RESOLUTION MICROSCOPY}

The aim of super-resolution microscopy is to provide similar resolution as EM but with light microscopy. In light microscopy the wave-like nature of light limits spatial resolution to half the wavelength of the observed light. This so called diffraction barrier was established by Ernst Abbé 140 years ago and is expressed by the formula:

$$
d=\frac{\lambda}{2(n \sin \theta)}
$$

(with $d$ the diameter of the spot generated by light of the wavelength $\lambda$ that travels in a medium with refractive index $n$ and converges with an angle $\theta$ ).

All microscopy technologies developed at the end of the twentieth century, such as confocal microscopy or TIRFM, improve the signal-to-noise ratio and thus produced highly contrasted and crisp images that showed a wealth of unprecedented details, but the resolution was still diffraction limited. An early approach was to use deconvolution algorithms to subtract the predicted point spread function (PSF) of individual fluorophores from the image and thus to reduce the contribution of diffracted light. This technique produces images with even better signal-to-noise ratio, but the resolution improvement is modest. Furthermore, due to the use of flawed PSFs, this technique is prone to generate artifacts like non existing signal patterns. The new super-resolution microscopy methods have addressed most of these problems and can achieve a resolution down to $10 \mathrm{~nm}$ (Hell, 2009; Dani and Huang, 2010; Tonnesen and Nagerl, 2013a).

\section{STRUCTURED ILLUMINATION MICROSCOPY (SIM)}

SIM achieves super-resolution by extracting fine structural details from the interference of a structure with predetermined illumination patterns. When a periodic illumination pattern, such as stripes, is applied to a fluorescent sample, an interference pattern is generated. The diffraction-limited fringes of this interference pattern, called moiré fringes, contain information about underlying structural pattern of the sample that cannot be observed with conventional light microscopy. By shifting and rotating the illumination pattern, sub-diffraction-limited structural information of the sample can be extracted from Fourier transformations of the resulting interference pattern (Gustafsson, 2000; Heintzmann et al., 2002) (Figure 2A). This produces a doubling of both lateral and axial resolution reaching 100 and $300 \mathrm{~nm}$, respectively. The resolution of the calculated image depends on the number of unique raw images acquired with different diffraction patterns/orientations. In order to generate a single plane highly resolved image a minimum of 15 different illumination patterns have to be applied. Currently, the minimum time required for this acquisition is about $300 \mathrm{~ms}$ for a single plane and about $8 \mathrm{~s}$ for $7 \mu \mathrm{m}$ thick chromaffin cells (Shao et al., 2011). This time frame is incompatible for life imaging of fast moving structures like LDCVs. However, it can easily be used to visualize 3D distribution of LDCVs in fixed cells without the need of lengthy procedures used in EM. Furthermore, it allows performing precise colocalization studies (Fiolka et al., 2012) in immune cells (Brown et al., 2011; Pattu et al., 2011; Matti et al., 2013) and neurons (Pielage et al., 2008; Sheets et al., 2012; Khuong et al., 2013) that might help to uncover interactions between proteins.

\section{PHOTOACTIVATED LOCALIZATION MICROSCOPY (PALM) AND STOCHASTIC OPTICAL RECONSTRUCTION MICROSCOPY (STORM)}

In PALM or STORM the resolution has been improved to much greater extent since they provide a lateral resolution of $10-30 \mathrm{~nm}$ and about $50 \mathrm{~nm}$ axial resolution (Betzig et al., 2006; Hess et al., 2006; Rust et al., 2006; Huang et al., 2008; Tatavarty et al., 2009; Shim et al., 2012). Both PALM and STORM rely on the property of certain fluorophores that can be photoactivated and switched on and off alternately (Folling et al., 2008; Shim et al., 2012). PALM relies on photoactivated fluorescent proteins (Betzig et al., 2006; Hess et al., 2006) while STORM, also called direct STORM (dSTORM), was developed using cyanide dyes (Bates et al., 2005; Rust et al., 2006; Heilemann et al., 2008). To generate superresolved images, the fluorescence of the sample is first entirely quenched with the normal excitation wavelength of the fluorophore, converting it from a ground state to a metastable dark state. Then fluorescence is slowly reactivated, either by itself or by a mild illumination with light at $405 \mathrm{~nm}$ (Figure 2B). 

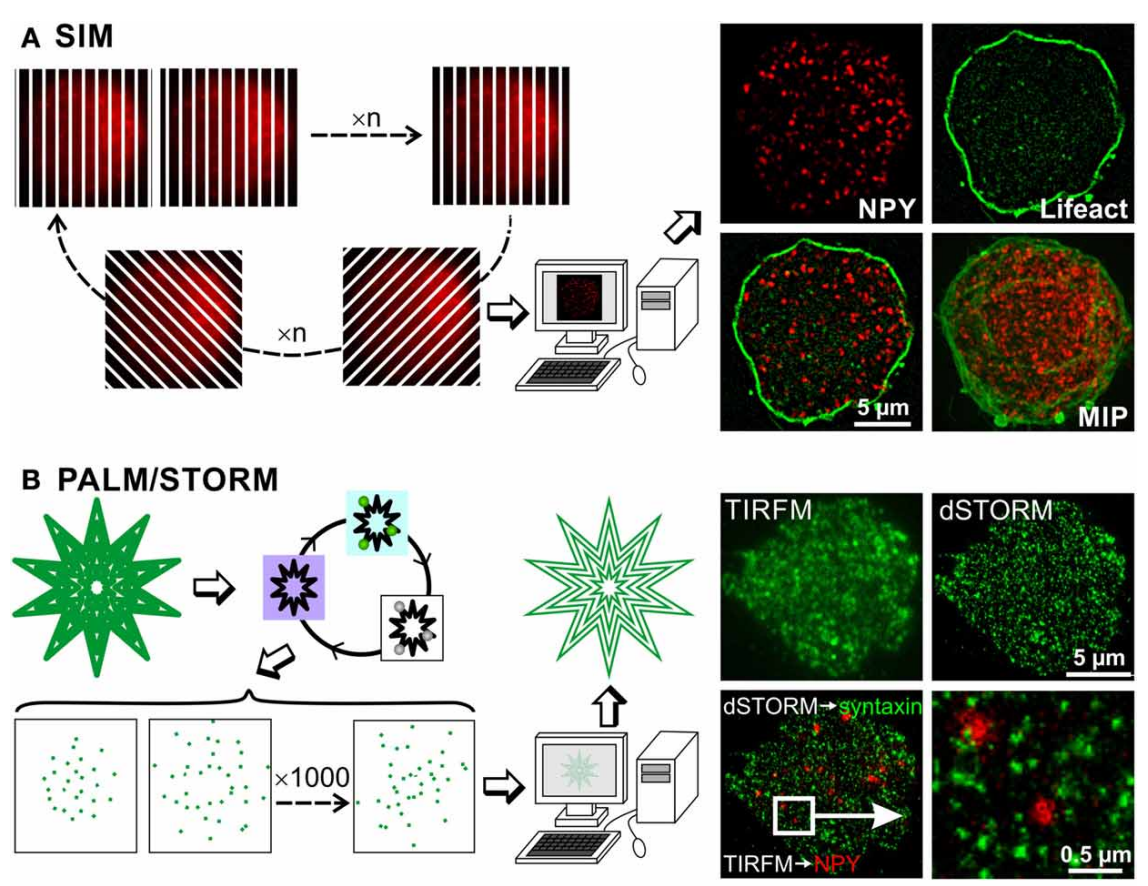

C STED microscopy
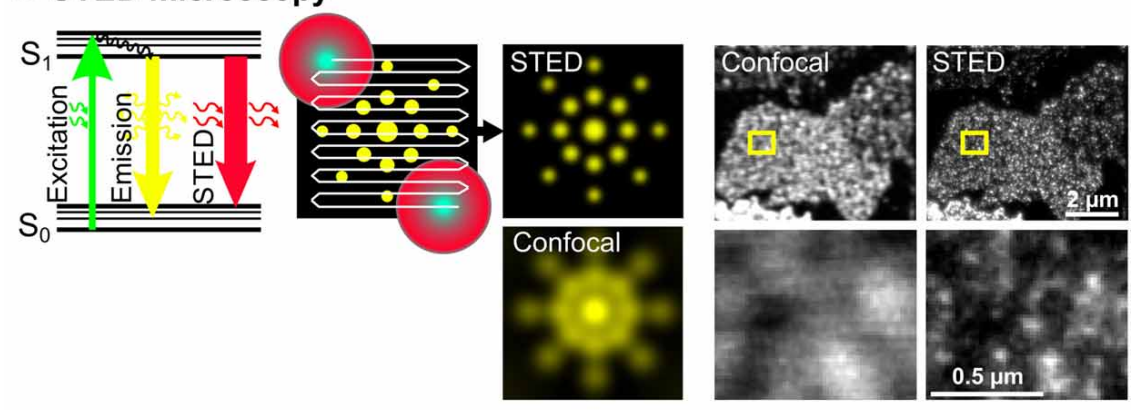

FIGURE 2 | Super-resolution microscopy methods to investigate chromaffin cell function. Basic principles of three super-resolution microscopy methods are depicted on the left, while some exemplary images using the respective technique are shown on the right. (A) In SIM microscopy a stripe pattern of light, which is shifted and rotated, is applied to the cell, so that the entire cell is illuminated within several images. These images contain sub-diffraction-limited structural information, which is extracted via computer processing using Fourier transformations. Resulting images have a lateral and axial resolution of 100 and $300 \mathrm{~nm}$, respectively. This can be appreciated on images of a bovine chromaffin cell, expressing NPY-mCherry and Lifeact-GFP labeling LDCVs and the F-actin, respectively. MIP: maximum intensity projection. (B) The principle of PALM and STORM exploit the properties of certain fluorophores that can be switched on and off. At first, all the fluorophores are pushed in a metastable dark state by illuminating them with their specific excitation light. Then, few molecules are brought back to the ground state using a mild illumination at usually $405 \mathrm{~nm}$ and visualized using their excitation light, which switches them off again These cycles are repeated up to 10,000 times generating a movie of blinking fluorophores. The labeled structure is then reconstituted by plotting their exact calculated position. This method generates images with lateral resolution of 10 to $30 \mathrm{~nm}$. This is shown on pictures of a bovine chromaffin cell. The LDCVs were marked by NPY-mCherry overexpression via Semliki Forest virus (shown in red) and the native syntaxin1 (shown in green) was labeled via monoclonal antibody (Synaptic Systems $\mathrm{GmbH}$ ) and Alexa 647 anti-mouse secondary antibody (Invitrogen). The gain of resolution can clearly be appreciated by comparing the pictures of syntaxin1 acquired with TIRFM and the picture of the same cell acquired with dSTORM. Due to dSTORM resolution, we observed that LDCVs were usually not located on syntaxin1 clusters. (C) As can be seen on the Jablonski diagram, the energy of an excited fluorescent molecule can be completely depleted by a photon that matches the energy difference between its excited (S1) and the ground electronic state (SO) before spontaneous fluorescence emission occurs. This process effectively depletes the S1 state of a fluorescent molecule by using a depleting laser that has high photon density, and a higher wavelength than the emission wavelength of the fluorophore. In this example a fluorescent protein such as YFP is excited at $514 \mathrm{~nm}$ and releases its fluorescent light at around $520 \mathrm{~nm}$. The stimulated emitted photons are not visible for the light detector (photomultiplier tube, avalanche photodiode) as they travel in the same direction as the stimulating laser beam but good emission filters are needed to block scattered light. Using this technique a STED beam consisting of a beam at the excitation wavelength surrounded by a donut shaped red light beam is applied to the probe. Normal emission occurs only from the central spot thus defining the size of the measured voxel. The STED beam scans the entire probe and the super resolved image is generated online. The lateral resolution is generally $20-50 \mathrm{~nm}$. This very high resolution can be appreciated on the images taken from Sieber et al. (2006) in which syntaxin1 was visualized using antibody labeling on membrane sheets generated from syntaxin 1 overexpressing PC12 cells. Images in the lower row correspond to a magnification of the small yellow square drawn on the images in the upper row. 
Importantly, not all the fluorescence is reactivated simultaneously, instead individual fluorophores are activated stochastically over time. They are visualized by the normal excitation light, which also brings them back in the dark state. A movie of blinking fluorescent molecules is then acquired over several minutes. Their position can be precisely determined using a simple Gaussian fit algorithm, as long as their fluorescent signals do not overlap. The quality of the position determination and thus of the final image resolution depends on the signal-to-noise ratio of the original image, on the internal jittering of the microscope and on the labeling density of the marked structure. The super-resolution image is then reconstructed by plotting the peak position of all blinking molecules. Depending on the sample size and the staining quality, 100 to 10,000 images have to be acquired to reconstruct one single image. Due to the large number of images that need to be recorded and their lengthy processing, this technique is not applicable to life cell imaging. However, PALM was recently used to follow single fluorescent proteins over time in living cells (Tatavarty et al., 2009; Izeddin et al., 2011; Sochacki et al., 2012). When comparing PALM to STORM, both produce images with similar resolution although STORM relies on antibody labeling which increases the length between the protein of interest and the fluorescent label (but see Ries et al., 2012). Furthermore, in STORM a toxic reducing buffer is used to reactivate the cyanide fluorophore (but see Klein et al., 2011). On the other hand, PALM relies on the overexpression of proteins tagged to individual fluorescent proteins, thus overexpression artifacts can occur. In brief, despite their respective weakness, PALM and STORM clearly close the gap between EM and light microscopy. They allow very precise localization of proteins in the cell without the need of complex immunogold techniques (Mennella et al., 2012; Macgillavry et al., 2013).

\section{STIMULATED EMISSION DEPLETION (STED) MICROSCOPY}

In contrast to the aforementioned super-resolution microscopy techniques, STED microscopy does not rely on post processing of blurry raw images but rather uses a specific illumination method and photo-physics to generate directly highly resolved images. In STED microscopy the excited fluorescent dye molecules return to the ground state (S0, Figure $2 \mathrm{C}$ ) via the process of stimulated emission, which is induced by a STED laser beam. The wavelength of the STED beam is at the tail end of the emission spectrum of the dye, where it does not excite the dye and where it can be spectrally separated from the spontaneous fluorescence. The fluorescence quenching scales with the intensity of the STED laser beam. The trick is to focus a depletion laser into a donut shape and superimpose this onto the focused laser excitation spot (Figure 2C middle). The spot in the middle of the donut, from which the normal emission occurs, can be made as small as $5.8 \mathrm{~nm}$ in diameter (Rittweger et al., 2009) but is usually 20 to $50 \mathrm{~nm}$ large. The emission depletion light beam can also be formed in an elongated spherical shape to limit the emission to a volume of $45 \mathrm{~nm}$ lateral and $108 \mathrm{~nm}$ axial resolution (Wildanger et al., 2009). The generation of an image is similar to classical confocal microscopy but due to the very small voxel size, the scanning speed is relatively slow. Improved hardware allowed the reduction of the excitation beam power and the implementation of live imaging. In 2008, Westphal et al. (2008) visualized moving recycling synaptic vesicles labeled with antibody and in the same year the technique was further adapted to visualize fluorescent proteins in living cells (Hein et al., 2008; Nagerl et al., 2008). Other developments made dual color imaging possible enabling colocalization studies (Donnert et al., 2007; Pellett et al., 2011; Tonnesen et al., 2011). STED provides a resolution that is comparable to EM to identify fine structures, such as Bruchpilot, at the active zone of the drosophila neuromuscular junction (Kittel et al., 2006) or dynamic changes of dendritic spines (Nagerl and Bonhoeffer, 2010; Blom et al., 2011; Urban et al., 2011; Tonnesen and Nagerl, 2013b).

\section{SUPER-RESOLUTION MICROSCOPY TO STUDY CHROMAFFIN CELLS: PRESENT AND FUTURE}

The impact of super-resolution microscopy in the field of neuroendocrinology is just about to spark. STED microscopy has been used to verify that the size of LDCVs was unaltered upon overexpression of a mutated Munc18-1 in neuroendocrine cells (Jorgacevski et al., 2011). SIM was applied to show that a mutated form of synaptobrevin was correctly sorted to LDCVs upon overexpression in mouse chromaffin cells (Borisovska et al., 2012). Furthermore, SIM was used to reveal that the cellular distribution of NPY-mCherry labeled LDCVs was normal and that it was not affected by t-SNARE and Munc18-2 overexpression (Hugo et al., 2013). PALM was used to uncover the size and the shape of clathrin coated pits in PC12 cells during reuptake of vesicular acetylcholine transporters (Sochacki et al., 2012). However, super-resolution microscopy has primarily been used to examine clustering of syntaxin 1 and SNAP 25 in the PM. The morphology and the dynamics of syntaxin 1 clusters were studied in cracked open PC12 cells using STED (Sieber et al., 2007). In contrast to what was shown using confocal microscopy, Lopez et al. (2009) and Bar-On et al. (2012) used PALM to demonstrate that syntaxin 1 and SNAP-25 clusters have a different morphology and that their colocalization is weak in PC12 cells. Additionally, PALM helped to establish that clustered SNARE proteins are not involved in LDCV docking or fusion (Yang et al., 2012). Using a very elegant combination of STED microscopy and Förster resonance energy transfer (FRET) Rickman et al. (2010) showed that overlapping t-SNARE clusters can contain fully assembled t-SNARE acceptor complexes. Finally, PIP2 and PIP3 clustering, that are believed to play a role in the t-SNARE organization, have been investigated using STORM (Wang and Richards, 2012).

Super-resolution microscopy will help us to understand the detailed molecular interactions in chromaffin cells function. As discussed in the introduction, one crucial issue is to clearly demonstrate the correlation between the functional and the morphological data on docking. Another important aspect in chromaffin cell research is to uncover at which time point during the exocytotic process, docking and priming factors bind to the release machinery of LDCVs. FRET is the tool of choice to demonstrate protein interactions in living cells. However, with the remarkable exceptions of Lam et al. (2010) and Zhao et al. (2013), several relatively inconclusive trials using FRET were made to study the interaction of the SNAREs during exocytosis. Thus, it is unlikely that FRET can be used to study the interaction of 
priming or docking factors with either the LDCVs or the SNARE core complex. One solution to address these problems might be to use a combination of super-resolution microscopy and EM, doing correlative light-electron microscopy (Sjollema et al., 2012). This technique will help us to uncover a relationship between the distance of LDCVs to the plasma membrane and their association with any of these proteins. Finally, aspects of LDCV biogenesis or protein recycling might be better understood using methods such as SIM in combination with molecular manipulations such as gene deletion or protein overexpression.

\section{ACKNOWLEDGMENTS}

Research in our lab has been funded by grants from the Deutsche Forschungsgemeinschaft (SFB 530 and SFB 894) and by competitive, local funding of the Saarland University.

\section{REFERENCES}

Ashery, U., Varoqueaux, F., Voets, T., Betz, A., Thakur, P., Koch, H., et al. (2000). Munc13-1 acts as a priming factor for large dense-core vesicles in bovine chromaffin cells. EMBO J. 19, 3586-3596. doi: 10.1093/emboj/19.14.3586

Axelrod, D. (1981). Cell-substrate contacts illuminated by total internal reflection fluorescence. J. Cell Biol. 89, 141-145. doi: 10.1083/jcb.89.1.141

Bar-On, D., Wolter, S., van de Linde, S., Heilemann, M., Nudelman, G., Nachliel, E., et al. (2012). Super-resolution imaging reveals the internal architecture of nano-sized syntaxin clusters. J. Biol. Chem. 287, 27158-27167. doi: 10.1074/jbc.M112.353250

Bates, M., Blosser, T. R., and Zhuang, X. (2005). Short-range spectroscopic ruler based on a single-molecule optical switch. Phys. Rev. Lett. 94, 108101. doi: 10.1103/PhysRevLett.94.108101

Becherer, U., Medart, M. R., Schirra, C., Krause, E., Stevens, D., and Rettig, J. (2012). Regulated exocytosis in chromaffin cells and cytotoxic T lymphocytes: how similar are they? Cell Calcium 52, 303-312. doi: 10.1016/j.ceca.2012.04.002

Becherer, U., and Rettig, J. (2006). Vesicle pools, docking, priming, and release. Cell Tissue Res. 326, 393-407. doi: 10.1007/s00441-006-0243-z

Betzig, E., Patterson, G. H., Sougrat, R., Lindwasser, O. W., Olenych, S., Bonifacino, J. S., et al. (2006). Imaging intracellular fluorescent proteins at nanometer resolution. Science 313, 1642-1645. doi: 10.1126/science.1127344

Blom, H., Ronnlund, D., Scott, L., Spicarova, Z., Widengren, J., Bondar, A., et al. (2011). Spatial distribution of Na+-K+-ATPase in dendritic spines dissected by nanoscale superresolution STED microscopy. BMC Neurosci. 12:16. doi: 10.1186/1471-2202-12-16

Borges, R., Camacho, M., and Gillis, K. D. (2008). Measuring secretion in chromaffin cells using electrophysiological and electrochemical methods. Acta Physiol. (Oxf.) 192, 173-184. doi: 10.1111/j.1748-1716.2007.01814.x

Borisovska, M., Schwarz, Y. N., Dhara, M., Yarzagaray, A., Hugo, S., Narzi, D., et al. (2012). Membrane-proximal tryptophans of synaptobrevin II stabilize priming of secretory vesicles. J. Neurosci. 32, 15983-15997. doi: 10.1523/JNEUROSCI.6282-11.2012

Borisovska, M., Zhao, Y., Tsytsyura, Y., Glyvuk, N., Takamori, S., Matti, U., et al. (2005). v-SNAREs control exocytosis of vesicles from priming to fusion. EMBO J. 24, 2114-2126. doi: 10.1038/sj.emboj.7600696

Brown, A. C. N., Oddos, S., Dobbie, I. M., Alakoskela, J., Parton, R. M., Eissmann, P., et al. (2011). Remodelling of Cortical Actin Where Lytic Granules Dock at Natural Killer Cell Immune Synapses Revealed by Super-Resolution Microscopy. PLoS Biol. 9:e1001152. doi: 10.1371/journal.pbio.1001152

Bruns, D., and Jahn, R. (2002). Molecular determinants of exocytosis. Pflugers Arch. 443, 333-338. doi: 10.1007/s00424-001-0742-4

Dani, A., and Huang, B. (2010). New resolving power for light microscopy: applications to neurobiology. Curr. Opin. Neurobiol. 20, 648-652. doi: 10.1016/j.conb.2010.07.006

de Wit, H. (2010). Morphological docking of secretory vesicles. Histochem. Cell Biol. 134, 103-113. doi: 10.1007/s00418-010-0719-5

de Wit, H., Walter, A. M., Milosevic, I., Gulyas-Kovacs, A., Riedel, D., Sorensen, J. B., et al. (2009). Synaptotagmin-1 docks secretory vesicles to syntaxin-1/SNAP25 acceptor complexes. Cell 138, 935-946. doi: 10.1016/j.cell.2009.07.027
Donnert, G., Keller, J., Wurm, C. A., Rizzoli, S. O., Westphal, V., Schonle, A., et al. (2007). Two-color far-field fluorescence nanoscopy. Biophys. J. 92, L67-L69. doi: 10.1529/biophysj.107.104497

Fiolka, R., Shao, L., Rego, E. H., Davidson, M. W., and Gustafsson, M. G. L. (2012). Time-lapse two-color 3D imaging of live cells with doubled resolution using structured illumination. Proc. Natl. Acad. Sci. U.S.A. 109, 5311-5315. doi: 10.1073/pnas.1119262109

Folling, J., Bossi, M., Bock, H., Medda, R., Wurm, C. A., Hein, B., et al. (2008). Fluorescence nanoscopy by ground-state depletion and single-molecule return. Nat. Methods 5, 943-945. doi: 10.1038/nmeth.1257

Gillis, K. D., Mossner, R., and Neher, E. (1996). Protein kinase C enhances exocytosis from chromaffin cells by increasing the size of the readily releasable pool of secretory granules. Neuron 16, 1209-1220. doi: 10.1016/S0896-6273(00) 80147-6

Gustafsson, M. G. (2000). Surpassing the lateral resolution limit by a factor of two using structured illumination microscopy. J. Microsc. 198, 82-87. doi: 10.1046/j.1365-2818.2000.00710.x

Heilemann, M., van de Linde, S., Schüttpelz, M., Kasper, R., Seefeldt, B., Mukherjee, A., et al. (2008). Subdiffraction-resolution fluorescence imaging with conventional fluorescent probes. Angew. Chem. Int. Ed. Engl. 47, 6172-6176. doi: 10.1002/anie. 200802376

Hein, B., Willig, K. I., and Hell, S. W. (2008). Stimulated emission depletion (STED) nanoscopy of a fluorescent protein-labeled organelle inside a living cell. Proc. Natl. Acad. Sci. U.S.A. 105, 14271-14276. doi: 10.1073/pnas. 0807705105

Heintzmann, R., Jovin, T. M., and Cremer, C. (2002). Saturated patterned excitation microscopy-a concept for optical resolution improvement. J. Opt. Soc. Am. A Opt. Image Sci. Vis. 19, 1599-1609. doi: 10.1364/JOSAA.19. 001599

Hell, S. W. (2009). Microscopy and its focal switch. Nat. Methods 6, 24-32. doi: 10.1038/nmeth.1291

Hess, S. T., Girirajan, T. P., and Mason, M. D. (2006). Ultra-high resolution imaging by fluorescence photoactivation localization microscopy. Biophys. J. 91, 4258-4272. doi: 10.1529/biophys.106.091116

Huang, B., Wang, W., Bates, M., and Zhuang, X. (2008). Three-dimensional superresolution imaging by stochastic optical reconstruction microscopy. Science 319, 810-813. doi: 10.1126/science.1153529

Hugo, S., Dembla, E., Halimani, M., Matti, U., Rettig, J., and Becherer, U. (2013). Deciphering dead-end docking of large dense core vesicles in bovine chromaffin cells. J. Neurosci. 33, 17123-17137. doi: 10.1523/JNEUROSCI.1589-13.2013

Izeddin, I., Specht, C. G., Lelek, M., Darzacq, X., Triller, A., Zimmer, C., et al. (2011). Super-resolution dynamic imaging of dendritic spines using a lowaffinity photoconvertible actin probe. PLoS ONE 6:e15611. doi: 10.1371/journal.pone.0015611

Jahn, R., and Fasshauer, D. (2012). Molecular machines governing exocytosis of synaptic vesicles. Nature 490, 201-207. doi: 10.1038/nature11320

Johns, L. M., Levitan, E. S., Shelden, E. A., Holz, R. W., and Axelrod, D. (2001). Restriction of secretory granule motion near the plasma membrane of chromaffin cells. J. Cell Biol. 153, 177-190. doi: 10.1083/jcb.153.1.177

Jorgacevski, J., Potokar, M., Grilc, S., Kreft, M., Liu, W., Barclay, J. W., et al. (2011). Munc18-1 tuning of vesicle merger and fusion pore properties. J. Neurosci. 31, 9055-9066. doi: 10.1523/JNEUROSCI.0185-11.2011

Kaplan, J. H., and Ellis-Davies, G. C. (1988). Photolabile chelators for the rapid photorelease of divalent cations. Proc. Natl. Acad. Sci. U.S.A. 85, 6571-6575. doi: 10.1073/pnas.85.17.6571

Kasai, H., Takahashi, N., and Tokumaru, H. (2012). Distinct initial SNARE configurations underlying the diversity of exocytosis. Physiol. Rev. 92, 1915-1964. doi: 10.1152/physrev.00007.2012

Khuong, T. M., Habets, R. L., Kuenen, S., Witkowska, A., Kasprowicz, J., Swerts, J., et al. (2013). Synaptic PI $(3,4,5) P 3$ is required for Syntaxin1A clustering and neurotransmitter release. Neuron 77, 1097-1108. doi: 10.1016/j.neuron.2013. 01.025

Kittel, R. J., Wichmann, C., Rasse, T. M., Fouquet, W., Schmidt, M., Schmid, A., et al. (2006). Bruchpilot promotes active zone assembly, $\mathrm{Ca}^{2+}$ channel clustering, and vesicle release. Science 312, 1051-1054. doi: 10.1126/science. 1126308

Klein, T., Löschberger, A., Proppert, S., Wolter, S., van de Linde, S., and Sauer, M. (2011). Live-cell dSTORM with SNAP-tag fusion proteins. Nat. Methods 8, 7-9. doi: 10.1038/nmeth0111-7b 
Lam, A. D., Ismail, S., Wu, R., Yizhar, O., Passmore, D. R., Ernst, S. A., et al. (2010). Mapping dynamic protein interactions to insulin secretory granule behavior with TIRF-FRET. Biophys. J. 99, 1311-1320. doi: 10.1016/j.bpj.2010.06.014

Lopez, I., Ortiz, J. A., Villanueva, J., Torres, V., Torregrosa-Hetland, C. J., del Mar Frances, M., et al. (2009). Vesicle Motion and Fusion are Altered in Chromaffin Cells with Increased SNARE Cluster Dynamics. Traffic 10, 172-185. doi: 10.1111/j.1600-0854.2008.00861.x

Macgillavry, H. D., Song, Y., Raghavachari, S., and Blanpied, T. A. (2013). Nanoscale Scaffolding Domains within the Postsynaptic Density Concentrate Synaptic AMPA Receptors. Neuron 78, 615-622. doi: 10.1016/j.neuron.2013.03.009

Matti, U., Pattu, V., Halimani, M., Schirra, C., Krause, E., Liu, Y., et al. (2013). Synaptobrevin2 is the v-SNARE required for cytotoxic T-lymphocyte lytic granule fusion. Nat. Commun. 4:1439. doi: 10.1038/ncomms 2467

Mennella, V., Keszthelyi, B., McDonald, K. L., Chhun, B., Kan, F., Rogers, G. C., et al. (2012). Subdiffraction-resolution fluorescence microscopy reveals a domain of the centrosome critical for pericentriolar material organization. Nat. Cell Biol. 14, 1159-1168. doi: 10.1038/ncb2597

Nagerl, U. V., and Bonhoeffer, T. (2010). Imaging living synapses at the nanoscale by STED microscopy. J. Neurosci. 30, 9341-9346. doi: 10.1523/JNEUROSCI.099010.2010

Nagerl, U. V., Willig, K. I., Hein, B., Hell, S. W., and Bonhoeffer, T. (2008). Live-cell imaging of dendritic spines by STED microscopy. Proc. Natl. Acad. Sci. U.S.A. 105, 18982-18987. doi: 10.1073/pnas.0810028105

Neher, E., and Marty, A. (1982). Discrete changes of cell membrane capacitance observed under conditions of enhanced secretion in bovine adrenal chromaffin cells. Proc. Natl. Acad. Sci. U.S.A. 79, 6712-6716. doi: 10.1073/pnas.79.21.6712

Neher, E., and Zucker, R. S. (1993). Multiple calcium-dependent processes related to secretion in bovine chromaffin cells. Neuron 10, 21-30. doi: 10.1016/08966273(93)90238-M

Nofal, S., Becherer, U., Hof, D., Matti, U., and Rettig, J. (2007). Primed vesicles can be distinguished from docked vesicles by analyzing their mobility. J. Neurosci. 27, 1386-1395. doi: 10.1523/JNEUROSCI.4714-06.2007

Oheim, M., Loerke, D., Stuhmer, W., and Chow, R. H. (1998). The last few milliseconds in the life of a secretory granule. Docking, dynamics and fusion visualized by total internal reflection fluorescence microscopy (TIRFM). Eur. Biophys. J. 27, 83-98. doi: 10.1007/s002490050114

Oheim, M., and Stuhmer, W. (2000). Tracking chromaffin granules on their way through the actin cortex. Eur. Biophys. J. 29, 67-89. doi: 10.1007/s002490050253

Pasche, M., Matti, U., Hof, D., Rettig, J., and Becherer, U. (2012). Docking of LDCVs is modulated by lower intracellular $\left[\mathrm{Ca}^{2+}\right]$ than priming. PLoS ONE 7:e36416. doi: 10.1371/journal.pone.0036416

Pattu, V., Qu, B., Marshall, M., Becherer, U., Junker, C., Matti, U., et al. (2011). Syntaxin7 Is Required for Lytic Granule Release from Cytotoxic T Lymphocytes. Traffic 12, 890-901. doi: 10.1111/j.1600-0854.2011.01193.X

Pellett, P. A., Sun, X., Gould, T. J., Rothman, J. E., Xu, M. Q., Correa, I. R. Jr, et al. (2011). Two-color STED microscopy in living cells. Biomed. Opt. Express 2, 2364-2371. doi: 10.1364/BOE.2.002364

Pielage, J., Cheng, L., Fetter, R. D., Carlton, P. M., Sedat, J. W., and Davis, G. W. (2008). A presynaptic giant ankyrin stabilizes the NMJ through regulation of presynaptic microtubules and transsynaptic cell adhesion. Neuron 58, 195-209. doi: 10.1016/j.neuron.2008.02.017

Pollard, H. B., Creutz, C. E., Fowler, V., Scott, J., and Pazoles, C. J. (1982). Calciumdependent regulation of chromaffin granule movement, membrane contact, and fusion during exocytosis. Cold Spring Harb. Symp. Quant. Biol. 46(Pt 2), 819-834. doi: 10.1101/SQB.1982.046.01.077

Rickman, C., Medine, C. N., Dun, A. R., Moulton, D. J., Mandula, O., Halemani, N. D., et al. (2010). t-SNARE Protein Conformations Patterned by the Lipid Microenvironment. J. Biol. Chem. 285, 13535-13541. doi: 10.1074/jbc.M109.091058

Ries, J., Kaplan, C., Platonova, E., Eghlidi, H., and Ewers, H. (2012). A simple, versatile method for GFP-based super-resolution microscopy via nanobodies. Nat. Methods 9, 582-584. doi: 10.1038/nmeth.1991

Rittweger, E., Wildanger, D., and Hell, S. W. (2009). Far-field fluorescence nanoscopy of diamond color centers by ground state depletion. Epl 84, 14001. doi: 10.1209/0295-5075/86/14001

Rizo, J., and Sudhof, T. C. (2012). The membrane fusion enigma: SNAREs, Sec1/Munc18 proteins, and their accomplices-guilty as charged. Annu. Rev. Cell Dev. Biol. 28, 279-308. doi: 10.1146/annurev-cellbio-101011-155818
Rust, M. J., Bates, M., and Zhuang, X. (2006). Sub-diffraction-limit imaging by stochastic optical reconstruction microscopy (STORM). Nat. Methods 3, 793-795. doi: 10.1038/nmeth929

Schneider, F. H., Smith, A. D., and Winkler, H. (1967). Secretion from the adrenal medulla: biochemical evidence for exocytosis. Br. J. Pharmacol. Chemother. 31, 94-104. doi: 10.1111/j.1476-5381.1967.tb01980.x

Shao, L., Kner, P., Rego, E. H., and Gustafsson, M. G. (2011). Super-resolution 3D microscopy of live whole cells using structured illumination. Nat. Methods 8, 1044-1046. doi: 10.1038/nmeth.1734

Sheets, L., Kindt, K. S., and Nicolson, T. (2012). Presynaptic CaV1.3 channels regulate synaptic ribbon size and are required for synaptic maintenance in sensory hair cells. J. Neurosci. 32, 17273-17286. doi: 10.1523/JNEUROSCI.300512.2012

Shim, S. H., Xia, C., Zhong, G., Babcock, H. P., Vaughan, J. C., Huang, B., et al. (2012). Super-resolution fluorescence imaging of organelles in live cells with photoswitchable membrane probes. Proc. Natl. Acad. Sci. U.S.A. 109, 13978-13983. doi: 10.1073/pnas.1201882109

Sieber, J. J., Willig, K. I., Heintzmann, R., Hell, S. W., and Lang, T. (2006). The SNARE motif is essential for the formation of syntaxin clusters in the plasma membrane. Biophys. J. 90, 2843-2851. doi: 10.1529/biophysj.105.079574

Sieber, J. J., Willig, K. I., Kutzner, C., Gerding-Reimers, C., Harke, B., Donnert, G., et al. (2007). Anatomy and dynamics of a supramolecular membrane protein cluster. Science 317, 1072-1076. doi: 10.1126/science.1141727

Sjollema, K. A., Schnell, U., Kuipers, J., Kalicharan, R., and Giepmans, B. N. (2012). Correlated light microscopy and electron microscopy. Methods Cell Biol. 111, 157-173. doi: 10.1016/B978-0-12-416026-2.00009-1

Sochacki, K. A., Larson, B. T., Sengupta, D. C., Daniels, M. P., Shtengel, G., Hess, H. F., et al. (2012). Imaging the post-fusion release and capture of a vesicle membrane protein. Nat. Commun. 3:1154. doi: 10.1038/ncomms2158

Sorensen, J. B. (2004). Formation, stabilisation and fusion of the readily releasable pool of secretory vesicles. Pflugers Arch. 448, 347-362. doi: 10.1007/s00424-0041247-8

Speidel, D., Bruederle, C. E., Enk, C., Voets, T., Varoqueaux, F., Reim, K., et al. (2005). CAPS1 regulates catecholamine loading of large dense-core vesicles. Neuron 46, 75-88. doi: 10.1016/j.neuron.2005.02.019

Stevens, D. R., Schirra, C., Becherer, U., and Rettig, J. (2011). Vesicle pools: lessons from adrenal chromaffin cells. Front. Synaptic Neurosci. 3:2. doi: 10.3389/fnsyn.2011.00002

Steyer, J. A., Horstmann, H., and Almers, W. (1997). Transport, docking and exocytosis of single secretory granules in live chromaffin cells. Nature 388, $474-478$.

Studer, D., Graber, W., Al-Amoudi, A., and Eggli, P. (2001). A new approach for cryofixation by high-pressure freezing. J. Microsc. 203, 285-294. doi: 10.1046/j.1365-2818.2001.00919.x

Sudhof, T. C. (2012). Calcium control of neurotransmitter release. Cold Spring Harb Perspect. Biol. 4:a011353. doi: 10.1101/cshperspect.a011353

Tatavarty, V., Kim, E. J., Rodionov, V., and Yu, J. (2009). Investigating subspine actin dynamics in rat hippocampal neurons with super-resolution optical imaging. PLoS ONE 4:e7724. doi: 10.1371/journal.pone.0007724

Tonnesen, J., Nadrigny, F., Willig, K. I., Wedlich-Soldner, R., and Nagerl, U. V. (2011). Two-color STED microscopy of living synapses using a single laser-beam pair. Biophys. J. 101, 2545-2552. doi: 10.1016/j.bpj.2011.10.011

Tonnesen, J., and Nagerl, U. V. (2013a). Superresolution imaging for neuroscience. Exp. Neurol. 242, 33-40. doi: 10.1016/j.expneurol.2012.10.004

Tonnesen, J., and Nagerl, U. V. (2013b). Two-color STED imaging of synapses in living brain slices. Methods Mol. Biol. 950, 65-80. doi: 10.1007/978-1-62703137-0-5

Toonen, R. F., Wierda, K., Sons, M. S., de Wit, H., Cornelisse, L. N., Brussaard, A., et al. (2006). Munc18-1 expression levels control synapse recovery by regulating readily releasable pool size. Proc. Natl. Acad. Sci. U.S.A. 103, 18332-18337. doi: $10.1073 /$ pnas.0608507103

Urban, N. T., Willig, K. I., Hell, S. W., and Nagerl, U. V. (2011). STED nanoscopy of actin dynamics in synapses deep inside living brain slices. Biophys. J. 101, 1277-1284. doi: 10.1016/j.bpj.2011.07.027

Vanhecke, D., Graber, W., and Studer, D. (2008). Close-to-native ultrastructural preservation by high pressure freezing. Methods Cell Biol. 88, 151-164. doi: 10.1016/S0091-679X(08)00409-3

Verhage, M., and Sorensen, J. B. (2008). Vesicle docking in regulated exocytosis. Traffic 9, 1414-1424. doi: 10.1111/j.1600-0854.2008.00759.x 
Villanueva, J., Torregrosa-Hetland, C. J., Garcia-Martinez, V., del Mar Frances, M., Viniegra, S., and Gutierrez, L. M. (2012). The F-actin cortex in chromaffin granule dynamics and fusion: a minireview. J. Mol. Neurosci. 48, 323-327. doi: 10.1007/s12031-012-9718-4

Voets, T., Neher, E., and Moser, T. (1999). Mechanisms underlying phasic and sustained secretion in chromaffin cells from mouse adrenal slices. Neuron 23, 607-615. doi: 10.1016/S0896-6273(00)80812-0

Wang, J., and Richards, D. A. (2012). Segregation of PIP2 and PIP3 into distinct nanoscale regions within the plasma membrane. Biol. Open 1, 857-862. doi: 10.1242/bio.20122071

Westphal, V., Rizzoli, S. O., Lauterbach, M. A., Kamin, D., Jahn, R., and Hell, S. W. (2008). Video-rate far-field optical nanoscopy dissects synaptic vesicle movement. Science 320, 246-249. doi: 10.1126/science.1154228

Wightman, R. M., Jankowski, J. A., Kennedy, R. T., Kawagoe, K. T., Schroeder, T. J., Leszczyszyn, D. J., et al. (1991). Temporally resolved catecholamine spikes correspond to single vesicle release from individual chromaffin cells. Proc. Natl. Acad. Sci. U.S.A. 88, 10754-10758. doi: 10.1073/pnas.88. 23.10754

Wildanger, D., Medda, R., Kastrup, L., and Hell, S. W. (2009). A compact STED microscope providing 3D nanoscale resolution. J. Microsc. 236, 35-43. doi: 10.1111/j.1365-2818.2009.03188.x

Yang, L., Dun, A. R., Martin, K. J., Qiu, Z., Dunn, A., Lord, G. J., et al. (2012). Secretory vesicles are preferentially targeted to areas of low molecular SNARE density. PLoS ONE 7:e49514. doi: 10.1371/journal.pone.0049514

Yizhar, O., and Ashery, U. (2008). Modulating vesicle priming reveals that vesicle immobilization is necessary but not sufficient for fusion-competence. PLoS ONE 3:e2694. doi: 10.1371/journal.pone.0002694
Yizhar, O., Matti, U., Melamed, R., Hagalili, Y., Bruns, D., Rettig, J., et al. (2004). Tomosyn inhibits priming of large dense-core vesicles in a calciumdependent manner. Proc. Natl. Acad. Sci. U.S.A. 101, 2578-2583. doi: 10.1073/ pnas.0308700100

Zhao, Y., Fang, Q., Herbst, A. D., Berberian, K. N., Almers, W., and Lindau, M. (2013). Rapid structural change in synaptosomal-associated protein 25 (SNAP25) precedes the fusion of single vesicles with the plasma membrane in live chromaffin cells. Proc. Natl. Acad. Sci. U.S.A. 110, 14249-14254. doi: $10.1073 /$ pnas. 1306699110

Conflict of Interest Statement: The authors declare that the research was conducted in the absence of any commercial or financial relationships that could be construed as a potential conflict of interest.

Received: 10 June 2013; accepted: 04 November 2013; published online: 25 November 2013.

Citation: Bost A, Pasche M, Schirra $C$ and Becherer U (2013) Super-resolution microscopy in studying neuroendocrine cell function. Front. Neurosci. 7:222. doi: 10.3389/fnins.2013.00222

This article was submitted to Neuroendocrine Science, a section of the journal Frontiers in Neuroscience.

Copyright (C) 2013 Bost, Pasche, Schirra and Becherer. This is an open-access article distributed under the terms of the Creative Commons Attribution License (CC BY). The use, distribution or reproduction in other forums is permitted, provided the original author(s) or licensor are credited and that the original publication in this journal is cited, in accordance with accepted academic practice. No use, distribution or reproduction is permitted which does not comply with these terms. 